\title{
PBL Quizzes and Their Effects on Student Performance
}

\author{
Mohand Alzughaibi, Mohammed Alotaibi, Faris Ahmed, Bader Alqahtani and Mohammed Bargo \\ College of Medicine, King Saud bin Abdulaziz University for Health Sciences, Riyadh, Kingdom of Saudi Arabia
}

\begin{abstract}
INTRODUCTION: Problem-Based Learning (PBL) was based on the fact that students must be the center of education. Problem-Based Learning (PBL) received criticism, arguing that no significant difference exist between it and conventional teaching. In our study, we examined the introduction of multiple mini quizzes after every PBL case as a method to improve student overall performance. METHODS: The study was a quasi-experimental interventional study that included 151 students from two batches (third and fourth year medical students attending respiratory and renal blocks, respectively). Each batch was divided and randomly assigned as "intervention groups" and "non-intervention" group. Intervention group was presented with mini quizzes of 10 questions each, after every PBL case. Midterm and final exam scores were compared between the two groups as a way of assessment of intervention effectiveness. RESULTS: In the respiratory block, when comparing the midterm and final results for intervention and non-intervention groups, the $P$ value was 0.46 in the midterm and 0.59 in the final exam. In the renal block, when comparing the midterm and final results for intervention and non-intervention groups, the $P$ value was 0.5 in the midterm and 0.32 in the final. CONCLUSION: Our study delineates the lack of objective effect on student performance measured by midterm and final exams by introducing quizzes after PBL sessions.
\end{abstract}

Key words: PBL, quiz, multiple choice question.

\section{Introduction}

Problem-Based Learning (PBL) has been labeled by some researchers as "most significant development in education over the past five decades" [1]. It relies on a philosophy centralizing the educational process around students. A stimulus is introduced to a small group of students to brainstorm and enhance their abilities in research, interpretation of medical knowledge and to empower their competencies in analyzing and looking for answers [2].

PBL has been widely applied in medical schools and institutions for the last 40 years because of its benefits [3]. It has been described as a stimulating, engaging, and useful learning tool [4]. It enhances learning, performance in exams and clinical competencies [5]. However, different opinions regarding PBL can be easily seen in literature. Some researchers propose that there is no significant, clear difference between PBL and conventional teaching. There have been some recommendations to merge it with conventional

Corresponding author: Mohand Alzughaibi, MBBS, research fields: medical education, urology. education to give a better outcome through a hybrid curriculum $[1,3,4]$.

Assessment is considered as an educational tool which enhances learning [6, 7]. Formative assessment is a predictor tool that helps students in acquiring knowledge, mastering skills and aids in assessing learning for both students and educators in a way that genuinely reflects strengths and weaknesses in the educational process [8-10]. On the other hand, summative assessment is mandatory and a formal tool that represents knowledge, skill and attitude of students [8].

In literature, there were distinct results about the efficacy of formative assessment in improving results in summative examination [11]. The relation of outcomes of quizzes and summative performance varied between no relations [12-14] and enhancement in summative examination result $[11,15,16]$. This enhancement was on short performance but not long performance [5] and only for students who scored under $61 \%$ [15].

The presence of different results in a limited number 
of studies in this area gives our hypothesis, "the combination of PBL and frequent mini quizzes will lead to more efficient result subjectively and objectively" a stronger ground. This method can drive students to give extra time to prepare assigned objectives and thus get the most benefit out of the PBL sessions which will be reflected on their overall summative assessment.

The purpose of this research is to study the relationship between post-PBL-problem quizzes and their effect on summative assessment.

\section{Methods}

This study was conducted at King Saud Bin Abdul-Aziz University for Health Sciences which includes different colleges in different cities (Riyadh, Jeddah and Alahsa). College of Medicine in Riyadh includes students in four levels who are distributed in two phases (basic sciences phase and clinical phase) and are both undergraduate and postgraduate students reaching up to 300 students.

PBL system was introduced since the college was established in 2004. Basic sciences were taught as different blocks. The university follows 11 steps in PBL distributed in three sessions per case during basic sciences phase and 7 steps PBL system distributed in two sessions per case during clinical phase.

The study was a quasi-experimental interventional study. Students enrolled in the study were third year medical students taking the respiratory block which is seven weeks long and fourth year students taking the renal block which is four weeks long. PBL groups are randomly assigned by Students Affair Department, in College of Medicine. PBL groups were randomly divided into two groups (Intervention and non-Intervention) by randomization in each level. Five groups of the respiratory block and five groups of the renal block were chosen. The rest of groups of both blocks were assigned as non-Intervention groups. The sample size was: 151 (around 74 students per batch). Our inclusion criteria were: all undergraduate medical students in basic sciences phase in Riyadh during the academic year 2013-2014 were included. They represent Batch 9 during the renal block and batch 10 during the respiratory block. The exclusion criterion was: any student who was in an intervention group and missed more than $50 \%$ of the quizzes was not included in the analysis. Questions were prepared by a committee of faculty members to ensure that the multiple-choice questions (MCQs) presented to the students were of high quality and covered PBL cases' objectives. After that, MCQs were further revised by the PBL coordinator.

At the end of the third session, a quiz of 10 questions was delivered to intervention groups with a total of 10 quizzes. Groups' tutors were responsible for distributing question papers, invigilating, keeping time and collecting answers. Students took one minute for each question. Quizzes were graded by the PBL coordinator. Quizzes' grades were given to assessment unit in academic affairs to be coded and to include grades of summative assessments for both groups (intervention group and non-intervention group). Analysis was done using SPSS software (version 23.0, IBM, Armonk, NY). Comparisons of two groups were done by using T-test. Students' names and numbers were coded during data collection in order to maintain confidentiality.

\section{Result}

The study includes a total of 151 students in two different academic years in which the first group enrolled in respiratory system block and the second group in renal system blocks. Each group was divided further in two groups (the intervention groups and the non-intervention groups) (Table 1).

In respiratory block, there are a total of 73 students in the block, where 41 of cases got the quizzes after each single PBL case; the remaining 32 controls did not receive any quizzes. For all students enrolled in the respiratory block results show an average midterm score of $32.8 \pm 4.2$ out of a 40 , while the average final score is $67.3 \pm 7.6$ out of 80 (Table 2). 
Table 1 Distribution of students (Intervention vs. Non-intervention).

\begin{tabular}{lll}
\hline The block & Respiratory & Renal \\
\hline Intervention & 41 & 42 \\
Non-intervention & 32 & 36 \\
\hline
\end{tabular}

Table 2 Measures of central tendency for respiratory block summative assessment.

\begin{tabular}{lll}
\hline Respiratory & Midterm & Final \\
\hline Mean & 32.8 & 67.3 \\
Standard deviation & 4.2 & 7.6 \\
Minimum & 22 & 44 \\
Maximum & 40 & 80 \\
\hline
\end{tabular}

For the intervention group $n=41$, the results show an average midterm score of $33.1 \pm 4$ while the average final score is $67.7 \pm 8.1$. For the non-intervention group, the results show an average midterm score of $32.4 \pm 4.4$ while the average final score is $66.7 \pm 7 . P$ value is 0.46 in the midterm and 0.59 in the final and that indicate insignificant difference between the mean of both groups in midterm and final (Table 3 ).

In the renal block, there are a total of 78 students. Forty-two students received the quizzes after each single PBL case. Thirty-sex students did not receive any form of additive assessment. For all students enrolled in renal block, results show an average midterm score of $35.5 \pm 4.9$, while the average final score is $67.8 \pm 10.5$ (Table 4 ).
For the case group $n=42$, the results show an average midterm score of $35.9 \pm 3.1$, while the average final score is $66.7 \pm 12.8$. For the control group $n=36$, the results show an average midterm score of $35.2 \pm 6.4$, while the average final score is $69.1 \pm 6.8$. $P$ value was 0.5 in the midterm and 0.32 in the final and that indicate insignificant variation between the mean of both groups in midterm and final (Table 5).

\section{Discussion}

The effects of assessment tools in enhancing students' performance in terms of knowledge gain and retention are well established [7]. Summative exams have a great influence on students in terms of creating a drive to read and review educational materials that are part of their exam carefully which will enrich their knowledge and lead to a better, more solid understanding.

The relationship between frequent quizzing and improved summative student performance have been studied before in multiple studies on different levels of education [16-18]. A positive impact on student results have been described in some studies [17-19]. Poljičanin et al. have described in their study an improved student scoring in written, practical and oral examination after introducing frequent quizzing as part

Table 3 Comparison between intervention and non-intervention groups (respiratory block) in terms of midterm and final assessment result.

\begin{tabular}{lllll}
\hline Respiratory & Total & Intervention & Non-intervention & $P$ value \\
$n=73$ & $n=41$ & $32.4 \pm 4.4$ & 0.54 \\
Midterm out of 40 & $32.8 \pm 4.2$ & $33.1 \pm 4.4$ & $66.7 \pm 7$ & 0.32 \\
Final out of 80 & $67.3 \pm 7.6$ & $67.7 \pm 8.1$ & 62.4 & \\
\hline
\end{tabular}

Table 4 Measures of central tendency for renal block summative assessment.

\begin{tabular}{lll}
\hline Renal & Midterm & Final \\
\hline Mean & 35.5 & 67.8 \\
Minimum & 29 & 58 \\
Maximum & 40 & 80 \\
\hline
\end{tabular}

Table 5 Comparison between intervention and non-intervention groups( renal block) in terms of midterm and final assessment result.

\begin{tabular}{lllll}
\hline \multirow{2}{*}{ Renal } & Total & Intervention & Non-intervention & \\
& $n=78$ & $n=42$ & $P$ value \\
\hline Midterm mean & $35.5 \pm 4.9$ & $35.9 \pm 3.1$ & $35.2 \pm 6.4$ & 0.54 \\
Final mean & $67.8 \pm 10.5$ & $66.7 \pm 12.8$ & $69.1 \pm 6.8$ & 0.32 \\
\hline
\end{tabular}


of anatomy curriculum [17].

The hypothesis of this study was that "the educational experience in a problem based system can be further enhanced in a subjective and objective manner by introducing frequent mini-quizzes delivered at the end of the third PBL session". Results of this study did not show a significant difference between the two groups in both the mid-terms and the final exams of the two blocks. These findings are in accordance with some studies that examined the effect of quizzes on student performance in different settings [12-14]. Pourahmad et al. conducted a study on medical students during pathophysiology course. Students were subjected to quizzes on certain topics from the curriculum and comparison was between students scoring in topics covered by quiz vs. topics not examined by quiz. The final result was a lack of significant difference in student scores [18]. Similar results were reported by Zamini et al. [20].

Although there have been multiple studies reporting the lack of improvement with multiple quizzing, other reasons might be contributing to the lack of statistically significant differences. The lack of incentive- in form of extra credit for instance- to participate might cause a lack of adequate preparation affecting finally the overall score. In studies where extra credit was allocated for students participating in quizzes, higher credit was associated with increased student participation and preparation [21].

Limitations that faced us in our study were the single institution setting and small sample size. Further research specifically designed to measure the magnitude of effect of quizzes in a PBL based system is required.

\section{Conclusion}

Our study delineates the lack of statistically significant differences in student performance, measured by summative assessment after introducing quizzes at the end of PBL sessions.

\section{References}

[1] Polyzois, I., Claffey, N., and Mattheos, N. 2010. "Problem-based Learning in Academic Health Education. A Systematic Literature Review." European Journal of Dental Education 14 (1): 55-64.

[2] Wood, D. F. 2003. "Problem Based Learning." BMJ: British Medical Journal 326 (7384): 328-30.

[3] Neville, A. 2009. "Problem-Based Learning and Medical Education Forty Years on."Med. Princ. Pract. 18 (1): 1-9.

[4] Nandi, P. L., Chan, J. N., Chan, C. P., Chan, P., and Chan, L. P. 2000. "Undergraduate Medical Education: Comparison of Problem-based Learning and Conventional Teaching." HKMJ 6 (3): 301-6.

[5] Raupach, T., Brown, J., Anders, S., Hasenfuss, G., and Harendza, S. 2013. "Summative Assessments are More Powerful Drivers of Student Learning than Resource Intensive Teaching Formats." BMC Medicine 11 (1): 61.

[6] Krupat, E., and Dienstag, J. 2009. "Commentary: Assessment Is an Educational Tool." Academic Medicine 84 (5): $548-50$.

[7] Wood, T. 2009. "Assessment Not Only Drives Learning, It May Also Help Learning." Medical Education 43 (1): 5-6.

[8] Rolfe, I., and McPherson, J. 1995. "Formative Assessment: How Am I Doing?” The Lancet 345 (8953): 837-9.

[9] Palmer, E., and Devitt, P. 2014. "The Assessment of a Structured Online Formative Assessment Program: A Randomised Controlled Trial." BMC Med. Educ. 14 (1): 8.

[10] Krasne, S., Wimmers, P., Relan, A., and Drake, T. 2006. "Differential Effects of Two Types of Formative Assessment in Predicting Performance of First-year Medical Students." Adv. Health Sci. Educ. Theory Pract. 11 (2): 155-71.

[11] Kibble, J. 2007. "Use of Unsupervised Online Quizzes as Formative Assessment in a Medical Physiology Course: Effects of Incentives on Student Participation and Performance." AJP: Advances in Physiology Education 31 (3): 253-60

[12] Lukić, I. K., Glunčić, V., Katavić, V., Petanjek, Z., Jalšovec, D., and Marušić, A. 2001. "Weekly Quizzes in Extended-Matching Format as a Means of Monitoring Students' Progress in Gross Anatomy." Annals of Anatomy 183 (6): 575-9.

[13] Peat, M., and Franklin, S. 2003. "Has Student Learning Been Improved by the Use of Online and Offline Formative Assessment Opportunities?" Austral. J. Educ. Technol. 19 (1): 87-99.

[14] Flannelly, L. T. 2001. "Using Feedback to Reduce Students' Judgment Bias on Test Questions." J. Nurs. Edu. 40 (1): 10-6.

[15] Azzi, A., Ramnanan, C., Smith, J., Dionne, É., and Jalali, A. 2014. "To Quiz or Not to Quiz: Formative Tests Help 
Detect Students at Risk of Failing the Clinical Anatomy Course." American Association of Anatomists 8 (5): 413-20.

[16] Still, M., and Still, J. 2015. "Contrasting Traditional In-Class Exams with Frequent Online Testing." Journal of Teaching and Learning with Technology 4 (2): 30.

[17] Poljičanin, A., Čarić, A., Vilović, K., Košta, V., Marinović Guić, M., Aljinović, J., and Grković, I. 2009. "Daily Mini Quizzes as Means for Improving Student Performance in Anatomy Course." Croatian Medical Journal 50 (1): 55-60.

[18] Pourahmad, M., Fadaei, S., Tadayon, S. M. K., and Zabetian, H. 2015. "The Effect of Quizzes on the Students' Scores in Final Exam.” Journal of Jahrom University of
Medical Sciences 10 (4): 37-41.

[19] Gholami, V., and Moghaddam, M. 2013. "The Effect of Weekly Quizzes on Students' Final Achievement Score." IJMECS 5 (1): 36-41.

[20] Zamini, G., Khadem Erfan, M. B., Rahmani, M. R., Khodavaisy, M. S., and Davari, B. 2013. "Effects of Frequent Announced Parasitology Quizzes on the Academic Achievement." Iranian J. Parasitol. 8 (4): 617-21.

[21] Kibble, J. 2007. "Use of Unsupervised Online Quizzes as Formative Assessment in a Medical Physiology Course: Effects of Incentives on Student Participation and Performance." AJP: Advances in Physiology Education 31 (3): 253-60. 